This manuscript has been authored by UT-Battelle, LLC under Contract No. DE-AC0500OR22725 with the U.S. Department of Energy. The United States Government retains and the publisher, by accepting the article for publication, acknowledges that the United States Government retains a non-exclusive, paid-up, irrevocable, world-wide license to publish or reproduce the published form of this manuscript, or allow others to do so, for United States Government purposes. The Department of Energy will provide public access to these results of federally sponsored research in accordance with the DOE Public Access Plan (http://energy.gov/downloads/doe-public-access-plan).

\title{
Tracer Study of Oxygen and Hydrogen Uptake by Mg Alloys in Air with Water Vapor
}

${ }^{1}$ M. P. Brady, ${ }^{2}$ M. Fayek, ${ }^{1}$ H.M. Meyer, III, ${ }^{1}$ D.N. Leonard, ${ }^{1,3}$ H. H. Elsentriecy, ${ }^{1}$ K. A. Unocic, ${ }^{1}$ L. M. Anovitz, ${ }^{1}$ E. Cakmak, ${ }^{1}$ J. R. Keiser, ${ }^{1}$ G.L. Song, and ${ }^{4}$ B. Davis

${ }^{1}$ Oak Ridge National Laboratory, Oak Ridge, TN USA

${ }^{2}$ University of Manitoba, Winnipeg, Manitoba Canada

${ }^{3}$ Central Metallurgical Research \& Development Institute, Cairo, Egypt

${ }^{4}$ Magnesium Elektron North America, Madison, IL USA

\section{Contact: bradymp@ornl.gov}

KeyWords: magnesium alloys, oxidation, hydrogen diffusion, secondary ion mass spectroscopy (SIMS), water vapor

\begin{abstract}
The oxidation of pure $\mathrm{Mg}, \mathrm{Mg}-3 \mathrm{Al}-1 \mathrm{Zn}$ (AZ31B), and $\mathrm{Mg}-1 \mathrm{Zn}-0.25 \mathrm{Zr}-<0.5 \mathrm{Nd}$ (ZE10A) was studied at $85{ }^{\circ} \mathrm{C}$ in humid air using sequential exposures with $\mathrm{H}_{2}{ }^{18} \mathrm{O}$ and $\mathrm{D}_{2}{ }^{16} \mathrm{O}$ for water vapor. Incorporation of ${ }^{18} \mathrm{O}$ in the hydroxideloxide films indicated that oxygen from water vapor participated in the reaction. Penetration of hydrogen into the underlying metal was observed, particularly for the $\mathrm{Zr}$ - and $\mathrm{Nd}$ - containing ZE1OA. Isotopic tracer profiles suggested a complex mixed inward/outward film growth mechanism.
\end{abstract}

Magnesium alloys are of great interest for the manufacture of vehicle parts, biomedical implants, and functional applications involving hydrogen storage, batteries, and fuel cells [1-3]. Understanding the high reactivity and film formation mechanism(s) associated with $\mathrm{Mg}$ alloys are a key to improving corrosion resistance, as well as tailoring corrosion reaction/stability 
behaviors for biomedical and functional use. Both $\mathrm{MgO}$ and $\mathrm{Mg}(\mathrm{OH})_{2}$ films are formed when Mg alloys are exposed to water [4,5].

The corrosion behavior of $\mathrm{Mg}$ alloys in aqueous solutions has been widely studied [e.g. 4, 5]. However, oxidation behavior studies at elevated temperatures have not been as widely pursued for $\mathrm{Mg}$ [6-12], but are relevant to applications such as automotive powertrain components, for example. The present authors recently demonstrated the feasibility of performing isotopic tracer studies of the film growth mechanism for the immersion of $\mathrm{Mg}$ in water, using sequential exposures in $\mathrm{D}_{2}{ }^{16} \mathrm{O}$ and/or $\mathrm{H}_{2}{ }^{18} \mathrm{O}$ water and secondary ion mass spectroscopy (SIMS) analysis [13]. The goal of the present work was to extend this experimental approach to study the oxidation film growth mechanism of $\mathrm{Mg}$ in hot humid air.

Ultrahigh purity $\mathrm{Mg}$ (UHP $\mathrm{Mg}$ ) and two $\mathrm{Mg}$ alloys: $\mathrm{AZ31B}$ to represent the $\mathrm{Mg}-\mathrm{Al}-\mathrm{Zn}$ alloy class and Elektron ${ }^{\circledR} 717$ (ZE10A grade, referred to as E717 for brevity), to represent the Mg-Zrrare earth alloy class, were selected for study (Table 1). The same materials batches and sample preparation methods as described in [13] were used in the present work. Test samples $\sim 9 \mathrm{~mm}$ in diameter and $\sim 1$ to $1.5 \mathrm{~mm}$ thick were wet ground to P1200 grit finish, cleaned with acetone and deionized water, and dried with an air stream [13]. Samples were stored in a desiccator for at least $24 \mathrm{~h}$ prior to the tracer studies [13].

Table 1. Alloy grain size and chemical composition of UHP Mg, AZ31B, and E717 determined by inductively coupled plasma atomic emission spectroscopy (ICP-AES) [from 13, 14]. The E717 contains $<0.5 \mathrm{wt} . \% \mathrm{Nd}$, the exact level of $\mathrm{Nd}$ is considered proprietary.

\begin{tabular}{|c|c|c|c|c|c|c|c|c|c|c|}
\hline \multirow{2}{*}{ Alloy } & \multirow{2}{*}{$\begin{array}{c}\text { Grain } \\
\text { Size } \\
\text { (microns) }\end{array}$} & \multicolumn{9}{|c|}{ Composition weight \% (wt.\%) } \\
\hline & & $\mathrm{Mg}$ & $\mathrm{Al}$ & $\mathrm{Zn}$ & $\mathrm{Zr}$ & $\mathrm{Mn}$ & $\mathrm{Nd}$ & $\mathrm{Fe}$ & $\mathrm{Cu}$ & $\mathrm{Ni}$ \\
\hline $\begin{array}{c}\text { UHP } \\
\text { Mg }\end{array}$ & $>1 \mathrm{~mm}$ & *99.98+ & 0.001 & 0.001 & $<0.001$ & $<0.001$ & $<0.001$ & 0.002 & $<0.001$ & $<0.001$ \\
\hline AZ31B & $10 \pm 5$ & 95.64 & 3.03 & 1.06 & 0.001 & 0.25 & $<0.001$ & 0.006 & 0.001 & 0.001 \\
\hline E717 & $14 \pm 10$ & Bal. & $<0.001$ & 1.18 & 0.25 & 0.007 & $<0.5$ & 0.004 & $<0.001$ & 0.001 \\
\hline
\end{tabular}

*0.01 wt.\% Pb detected in one UHP Mg sample (repeat did not show $\mathrm{Pb}$ )

Oxidation exposures were done at $85^{\circ} \mathrm{C}$ in humid air using a sealed stainless steel reaction vessel approach previously developed for geochemical hydration studies [15]. The reaction vessels $(\sim 24$ $\mathrm{cm}^{3}$ ) contained an inner Teflon liner to which $2 \mathrm{ml}$ of isotopic tracer water was added, with the 
test sample suspended above the water in the vapor phase (humid air) in a Teflon mesh basket. The reaction vessels were then sealed and placed in a covered aluminum block holder inside of a convection oven at $85^{\circ} \mathrm{C}$. At this temperature, these vessel and fluid volumes result in a twophase (liquid/vapor) system with an equilibrium water vapor pressure of 0.58 bar. Duplicate sequential exposure time procedures used in the previous water immersion isotopic tracer study [13] were adopted for the present work. The test samples were exposed at $85^{\circ} \mathrm{C}$ for $4 \mathrm{~h}$ to air with water vapor derived from $\mathrm{H}_{2}{ }^{18} \mathrm{O}$, and immediately removed and relocated to a second reaction vessel that was then sealed and heated to $85^{\circ} \mathrm{C}$ for $20 \mathrm{~h}$ exposure to air with water vapor derived from $\mathrm{D}_{2}{ }^{16} \mathrm{O}$ (sample relocation time $\sim 1$ minute). (For brevity, this exposure protocol will be referred to as "sequential tracer $85^{\circ} \mathrm{C}$ humid air oxidation" in the remainder of the text). The $\mathrm{H}_{2}{ }^{18} \mathrm{O}$ water was obtained as $>98$ atomic percent (at.\%) ${ }^{18} \mathrm{O}$ water from Campro Scientific, Bobinestraat 7-6 $3903 \mathrm{KE}$ Veenendaal, The Netherlands [13]. The $\mathrm{D}_{2}{ }^{16} \mathrm{O}$ was obtained as 99.96 at.\% isotope purity from Cambridge Isotope Laboratories, Inc., Andover, MA USA.

After exposure, samples were characterized by SIMS profiling, $\mathrm{X}$-ray photoelectron spectroscopy (XPS), X-ray diffraction (XRD), and surface and cross-section scanning and transmission electron microscopy (SEM, TEM). The SIMS data was obtained by sputtering with a 45 to 50 nA primary beam of $\mathrm{Cs}^{+}$; a $400 \mu \mathrm{m}$ field aperture and $150 \mu \mathrm{m}$ contrast aperture were used to select ions from the center of the rastered area, with ions effectively obtained primarily from a 75 micron diameter region [13]. In order to optimize detection, oxygen and hydrogen isotopes were analyzed separately, i.e. different sputtering locations on the same sample [13]. The XPS analysis used a monochromated, micro-focusing, Al Ka X-ray source $(1486.6 \mathrm{eV})$ with a $400 \mu \mathrm{m} \mathrm{X-ray}$ spot size for maximum signal and to obtain an average surface composition over the largest possible area [14]. Depth profiling analyses were conducted with a Thermo Scientific EX06 argon ion gun operated at $1000 \mathrm{eV}$ and rastered over a $2 \mathrm{~mm} \times 4 \mathrm{~mm}$ area [14]. STEM specimens of the film and metal/film interface regions were prepared via the focus ion beam (FIB) in-situ lift-out technique [14]. Further details of the SIMS, XPS, and STEM characterization procedures are described in [13] and [14].

Cross-section TEM images of UHP Mg, E717, and AZ31B after the sequential tracer $85^{\circ} \mathrm{C}$ humid air oxidations are shown in Fig. 1. The film formed on the UHP Mg was the thickest of the 3 materials, with regions ranging from less than $100 \mathrm{~nm}$ to areas with nodule-like protrusions 
extending several microns into the metal (Fig. 1a). The film formed on E717 was generally in the 100-400 nm range. The E717 contains nanoscale second phase particles previously identified as $\mathrm{Zn}_{2} \mathrm{Zr}_{3}[13,14]$; these particles (bright phase in Fig 1b) were evident both within the film and the underlying alloy (Fig. 1b, d). The film formed on AZ31B in sequential tracer $85^{\circ} \mathrm{C}$ humid air oxidation (Fig. 1c) was also in the $\sim 100-400 \mathrm{~nm}$ range, but with layered, nodule-like outer growths overlying a $\mathrm{Zn}$ and $\mathrm{Al}$ enriched region at the film-metal interface (Fig $1 \mathrm{c}$, e). The film morphologies observed in sequential tracer $85^{\circ} \mathrm{C}$ humid air oxidation for UHP $\mathrm{Mg}$ and E717 were similar to those observed in the previous work $[13,14]$ for a sequential tracer roomtemperature water immersion of $4 \mathrm{~h}$ in $\mathrm{D}_{2}{ }^{16} \mathrm{O}$ and $20 \mathrm{~h}$ in $\mathrm{H}_{2}{ }^{18} \mathrm{O}$ for UHP $\mathrm{Mg}$ and E717. However, for AZ31B in the sequential tracer room-temperature water immersion [13,14], only a thin $(\sim 100 \mathrm{~nm})$ relatively uniform film was observed, in contrast to the outward nodule-like growths observed in sequential tracer $85^{\circ} \mathrm{C}$ humid air oxidation (Fig. 1c).

Analysis by grazing incidence XRD identified substrate Mg metal peaks, with only a single small film peak consistent with the (001) of $\mathrm{Mg}(\mathrm{OH})_{2}$ also detected. Limited TEM selected area diffraction (SAD) analysis also suggested the films were primarily $\mathrm{Mg}(\mathrm{OH})_{2}$, but also contained $\mathrm{MgO}$ (confirmed by SAD only for E717). XPS was therefore used to better characterize the film structure (Fig. 2). The XPS analysis was based on fitting of the O1s, with $\mathrm{Mg}(\mathrm{OH})_{2}$ at $\sim 532.4 \mathrm{eV}$, $\mathrm{O}$ that is associated with Ar ion sputter damage of $\mathrm{Mg}(\mathrm{OH})_{2}$ at $\sim 529.7 \mathrm{eV}$, and $\mathrm{O}$ that is associated with $\mathrm{MgO}$ at $\sim 531.2 \mathrm{eV}$, with further corroboration from the $\mathrm{Mg} 2 \mathrm{p}$ spectra. However, due to fitting complexities resulting from sputter damage of $\mathrm{Mg}(\mathrm{OH})_{2}$ during profiling, the fitted fractions of $\mathrm{Mg}(\mathrm{OH})_{2}$ and $\mathrm{MgO}$ (Fig 2) should be considered semi-quantitative. For UHP Mg, E717, and AZ31B in sequential tracer $85^{\circ} \mathrm{C}$ humid air oxidation, the outer films were rich in $\mathrm{Mg}(\mathrm{OH})_{2}$, particularly for UHP $\mathrm{Mg}$, with increasing amounts of $\mathrm{MgO}$ detected on sputter profiling through the films formed on E717 (data stopped at 1100 s sputtering due to charging) and AZ31B (Fig. 2). In contrast, the films formed on these alloys in sequential tracer roomtemperature water immersion [13,14] were primarily $\mathrm{MgO}$, with a minor amount of $\mathrm{Mg}(\mathrm{OH})_{2}$ at the outer surface. (It should be noted that the $\mathrm{MgO}$ formed in room-temperature water was "partially" hydrated as above background $\mathrm{H}$ signal was still detected throughout the MgO-base films by SIMS $[13,14])$. 
Figures 3 a,b show SIMS profile data through the UHP Mg, E717, and AZ31B films after the sequential tracer $85^{\circ} \mathrm{C}$ humid air oxidation. Consistent with the TEM cross-sections and XPS data (Figs 1,2), the oxygen isotope depth profiles for the UHP Mg film extended deeper (thicker) than the films formed on E717 and AZ31B. The ${ }^{18} \mathrm{O}$ and ${ }^{16} \mathrm{O}$ signals decreased to $\sim \leq 10$ counts per second (c/s) and 100-1000 c/s background levels, respectively, after $\sim 3000 \mathrm{~s}$ of sputtering for E717 and AZ31B, and $\sim 6000-7000 \mathrm{c} / \mathrm{s}$ of sputtering for UHP $\mathrm{Mg}$ (background ${ }^{16} \mathrm{O}$ and ${ }^{18} \mathrm{O}$ intensities determined from as-polished surfaces [13]). ${ }^{18} \mathrm{O}$ intensities of $\sim 10,000 \mathrm{c} / \mathrm{s}$ were observed at the film surfaces (> 1000x above background), which suggests preferential oxidation by oxygen in the water vapor derived from the $\mathrm{H}_{2}{ }^{18} \mathrm{O}$, rather than oxygen in the air. Similar behavior consistent with preferential water vapor reaction behavior has been observed in hightemperature humid air oxidation of Fe- and Ni-base alloys [16, 17].

Film surface D intensities for all 3 materials reached $\sim 500,000 \mathrm{c} / \mathrm{s}$, and leveled out to 2500 $3000 \mathrm{c} / \mathrm{s}$ for E717 and $150-300 \mathrm{c} / \mathrm{s}$ for UHP Mg and AZ31B (Fig. 3b); whereas background D signal intensity levels in as-polished control surfaces were $<10 \mathrm{c} / \mathrm{s}$ [13]. Significant (above background) D intensities were evident at sputtering depths beyond where the $\mathrm{O}$ species had decreased to background levels (Figs $3 \mathrm{a}, \mathrm{b}$ ). This indicates penetration of $\mathrm{D}$ beyond the $\mathrm{Mg}(\mathrm{OH})_{2}-\mathrm{MgO}$ films and into the underlying metal on sequential tracer $85^{\circ} \mathrm{C}$ humid air oxidation, particularly for the Zr- and Nd- containing E717. Similar D penetration through the film and into underlying metal was also observed in sequential tracer room-temperature water immersion, again particularly for E717 [13].

Figures $3 \mathrm{c}$, d show ${ }^{18} \mathrm{O}$ and D fraction plots for the UHP $\mathrm{Mg}$, E717, and AZ31B films after sequential tracer $85^{\circ} \mathrm{C}$ humid air oxidation, and comparison data [13] from sequential tracer room-temperature water immersion. In the room temperature water immersion data ("W" in plots), the ${ }^{18} \mathrm{O}$ fraction was highest at the outer film surface for UHP Mg, E717, and AZ31B $(\sim 0.2-0.4)$, with a rapid decrease with sputtering depth, consistent with inward dominated film growth (Fig. 3c) [13]. However, much different shaped profiles were observed in the sequential tracer $85^{\circ} \mathrm{C}$ humid air oxidation (Fig. 3d). The ${ }^{18} \mathrm{O}$ fractions were highest in the inner film region near the film-metal interface for AZ31B ( $\sim 0.05$ to 0.1$)$, suggesting a strong component of 
outward film growth for the $20 \mathrm{~h}$ water vapor derived from $\mathrm{D}_{2}{ }^{16} \mathrm{O}$ step. The ${ }^{18} \mathrm{O}$ fraction profile for UHP Mg peaked at 0.3 in the middle of the film, suggesting mixed inward/outward growth. Mixed inward/outward film growth was also evident in the ${ }^{18} \mathrm{O}$ fraction profile data for E717, with peak values of $\sim 0.15-0.2$ observed both at the outer film surface and in the inner film region near the film-metal interface (Fig. 3c).

Much higher peak D fractions ( $\sim .5$ to 0.6$)$ were observed in $85^{\circ} \mathrm{C}$ humid air oxidation data than room-temperature water immersion ( 0.05 to 0.25) for UHP Mg, E717, and AZ31B (Fig 3d). The sequential tracer $85^{\circ} \mathrm{C}$ humid air oxidation $\mathrm{D}$ fraction profiles were of similar shape for all 3 materials, with a rapid increase to peak values after $\sim 500-1000 \mathrm{~s}$ of sputtering for E717 and AZ31B, and 2000-3000 s for UHP Mg. These humid air profiles are different in shape than those observed in room-temperature water, which monotonically decreased from the surface inward for UHP Mg and AZ31B, but peaked near the film-metal interface for E717 (Fig. 3d), suggesting inward lattice D diffusion in room-temperature water for UHP $\mathrm{Mg}$ and $\mathrm{AZ} 31 \mathrm{~B}$, and short-circuit inward diffusion for E717 [13].

The sequential tracer $85^{\circ} \mathrm{C}$ humid air oxidation $\mathrm{D}$ fraction profiles are complex to interpret, but suggest a strong component of inward film growth for UHP Mg, E717 and AZ31B; as near-peak D fraction values occur in the outer regions of the films, although not at the film surface (Fig. 3d). This D uptake mechanism is in partial contrast to the sequential tracer $85^{\circ} \mathrm{C}$ humid air oxidation ${ }^{18} \mathrm{O}$ fraction data (Fig. 3c), which suggested a strong component of outward growth for AZ31B and mixed inward/outward film growth for UHP $\mathrm{Mg}$ and E717. It is also not readily reconciled with morphological features observed in the film cross-section TEM images (Fig. 1). Outward nodule-like film formation was observed for AZ31B (Fig 1c), but local extensive nodular inward penetrations were observed in UHP Mg (Fig 1a), and the incorporation of $\mathrm{Zn}_{2} \mathrm{Zr}_{3}$ particles into the film formed on E717 (Fig. 1b), both of which indicate a strong component of inward growth behavior. One possible interpretation is the initial formation of $\mathrm{MgO}$ by mixed outward/inward growth in $85^{\circ} \mathrm{C}$ humid air oxidation, followed by extensive inward hydration and further oxidation of the initially-formed $\mathrm{MgO}$ to $\mathrm{Mg}(\mathrm{OH})_{2}$. Determination of how the film phase makeup and morphology initially establishes and then evolves with time will be needed to further delineate the complex $\mathrm{Mg}$ film growth mechanism in hot humid air. 


\section{Acknowledgements}

The authors thank R. Sharpe, D.W. Coffey, T.M. Lowe, T. Geer and T.L. Jordan for assistance with the experimental work. J. Thomson, S. Dryepondt, and B.A. Pint provided comments for manuscript. This research was sponsored by the U.S. DOE EERE Vehicle Technologies Office. Research supported by ORNL's Shared Research Equipment (ShaRE) User Program, which is sponsored by the Office of Basic Energy Sciences, U.S. DOE.

\section{References}

[1] A.A. Luo, JOM-Journal of the Minerals Metals \& Materials Society, 54 (2002) 42-48.

[2] I. Johnson, H.N. Liu, Plos One, 8 (2013).

[3] B. Sakintuna, F. Lamari-Darkrim, M. Hirscher, Int. J. Hydrogen Energy, 32 (2007) 11211140 .

[4] G.-L. Song, M. Liu, Corros. Sci., 62 (2012) 61-72.

[5] M. Taheri, R.C. Phillips, J.R. Kish, G.A. Botton, Corros. Sci., 59 (2012) 222-228.

[6] F. Czerwinski, Acta Mater., 50 (2002) 2639-2654.

[7] L.P.H. Jeurgens, M.S. Vinodh, E.J. Mittemeijer, Acta Mater., 56 (2008) 4621-4634.

[8] F. Czerwinski, JOM, 64 (2012) 1477-1483.

[9] T.-S. Shih, J.-B. Liu, P.-S. Wei, Mater. Chem. Phys., 104 (2007) 497-504.

[10] J.W. Liu, Y. Li, F.H. Wang, Oxid. Met., 71 (2009) 319-334.

[11] H. Saleh, T. Weling, J. Seidel, M. Schmidtchen, R. Kawalla, F.O.R.L. Mertens, H.P. Vogt, Oxid. Met., 81 (2014) 529-548.

[12] V. Fournier, P. Marcus, I. Olefjord, Surf. Interface Anal., 34 (2002) 494-497.

[13] M.P. Brady, M. Fayek, H.H. Elsentriecy, K.A. Unocic, L.M. Anovitz, J.R. Keiser, G.L. Song, B. Davis, J. Electrochem. Soc., 161 (2014) C395-C404.

[14] K.A. Unocic, H.H. Elsentriecy, M.P. Brady, H.M. Meyer, G.L. Song, M. Fayek, R.A. Meisner, B. Davis, J. Electrochem. Soc., 161 (2014) C302-C311.

[15] L.M. Anovitz, J.M. Elam, L.R. Riciputi, D.R. Cole, Archaeometry, 46 (2004) 301-326.

[16] Q. Lu, G. Hultquist, Corros. Sci. 36 (1994) 927-939.

[17] W.J. Quadakkers, J. Zurek, M. Hansel, JOM, 61 (2009) 44-50. 


\section{Figure Captions}

Fig. 1- Cross-section TEM images and maps after sequential tracer $85^{\circ} \mathrm{C}$ humid air oxidation (0.58 bar): a) UHP Mg; b, d) E717, and c, e) AZ31B

Fig. 2- Fitted XPS data after sequential tracer $85^{\circ} \mathrm{C}$ humid air oxidation ( 0.58 bar). $\mathrm{AZ}=\mathrm{AZ31B}$, $\mathrm{E} 7=\mathrm{E} 717, \mathrm{Mg}=\mathrm{UHP} \mathrm{Mg}$

Fig. 3- SIMS data after sequential tracer $85^{\circ} \mathrm{C}$ humid air oxidation $(0.58$ bar $)$ : a) ${ }^{18} \mathrm{O}$ and ${ }^{16} \mathrm{O}$ profiles; b) D and H profiles; c) Fraction ${ }^{18} \mathrm{O} /\left({ }^{18} \mathrm{O}+{ }^{16} \mathrm{O}\right)$; d) Fraction $\mathrm{D} /(\mathrm{D}+\mathrm{H})$. Data marked "W" is for sequential tracer room-temperature water immersion data from [13]. AZ = AZ31B, E7 = $\mathrm{E} 717, \mathrm{Mg}=\mathrm{UHP} \mathrm{Mg}$ 

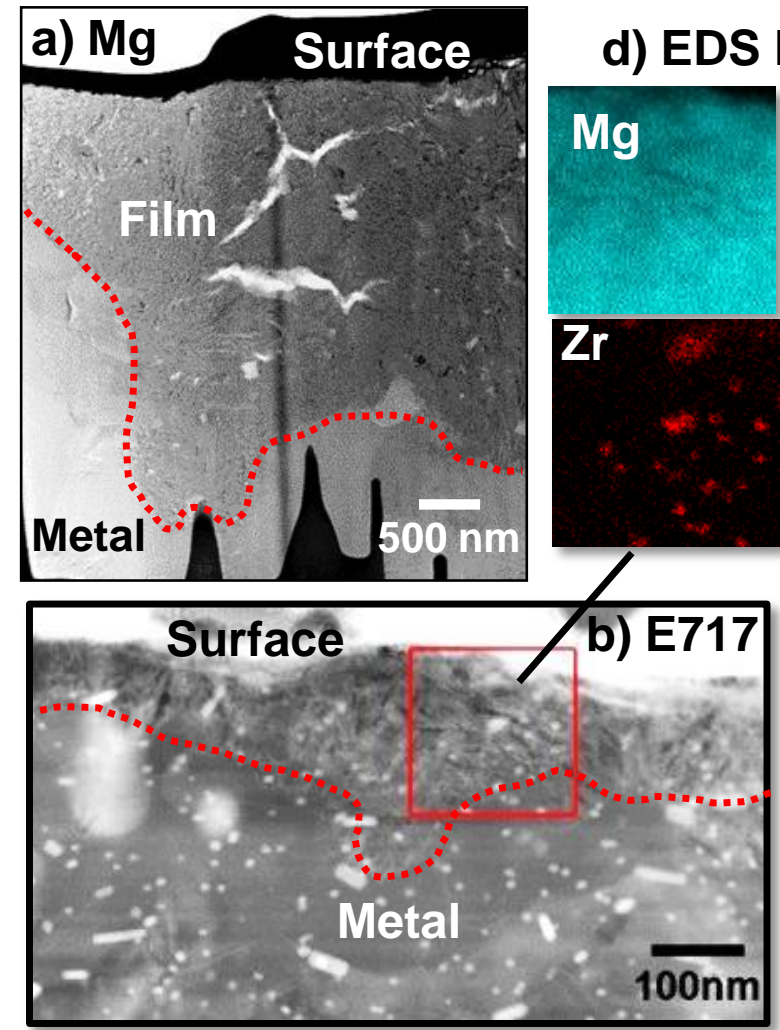

d) EDS Map E717
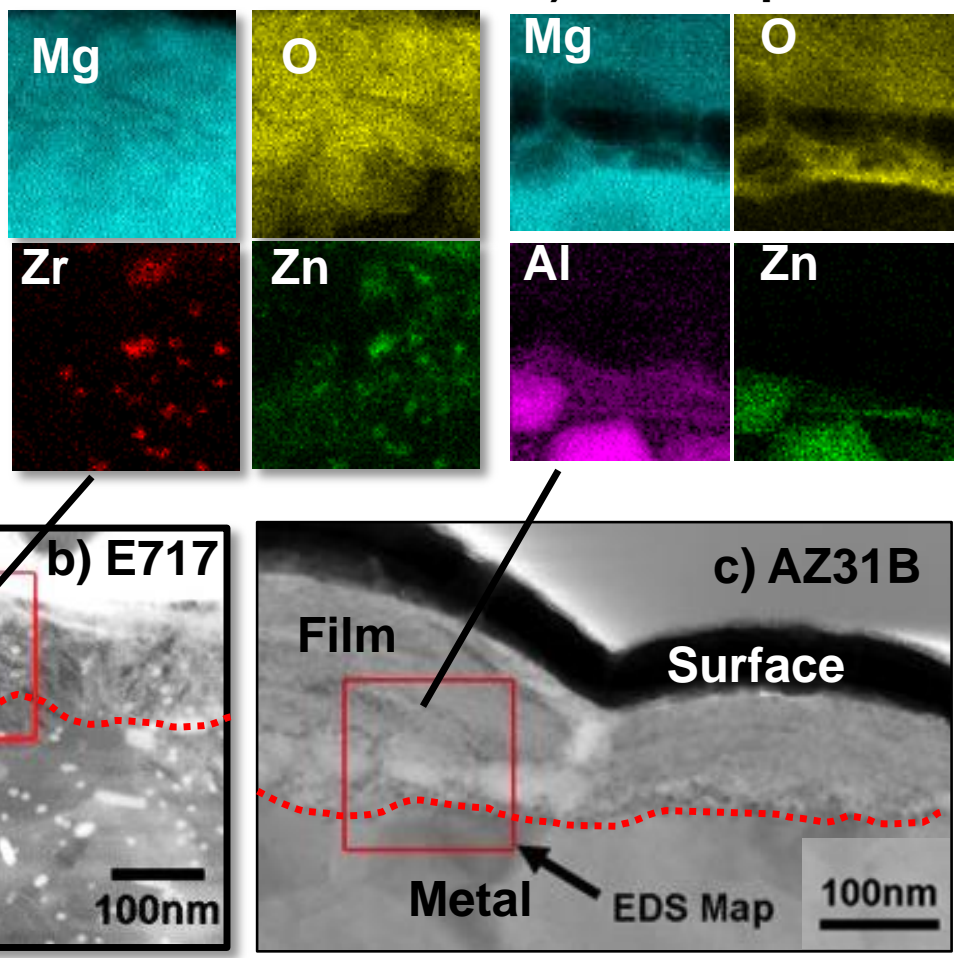

Fig. 1- Cross-section TEM images and maps after sequential tracer $85^{\circ} \mathrm{C}$ humid air oxidation (0.58 bar): a) UHP Mg; b, d) E717, and c, e) AZ31B

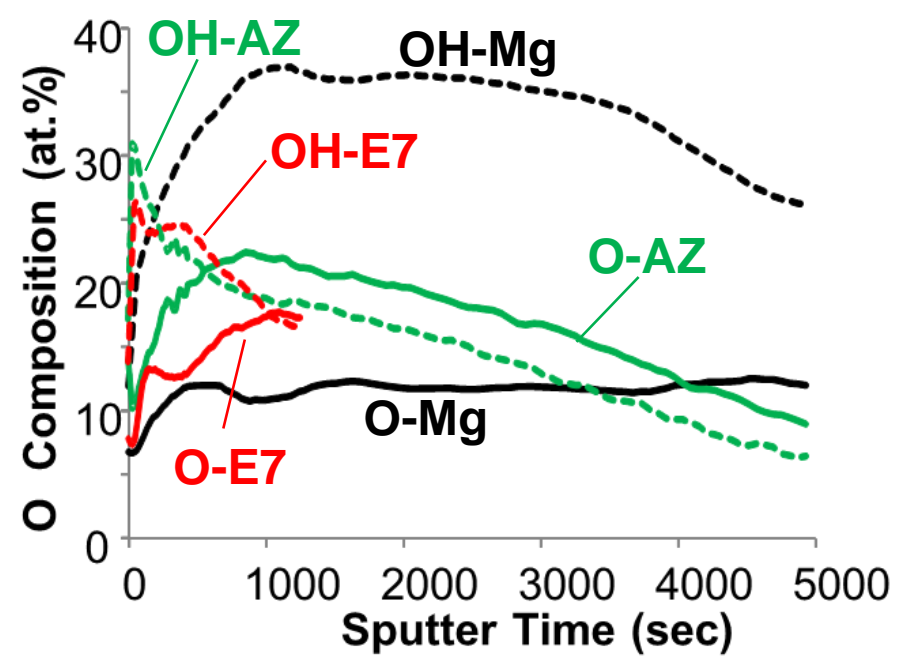

Fig. 2- Fitted XPS data after sequential tracer $85^{\circ} \mathrm{C}$ humid air oxidation $(0.58$ bar $) . A Z=A Z 31 B, E 7$ $=\mathrm{E} 717, \mathrm{Mg}=\mathrm{UHP} \mathrm{Mg}$ 

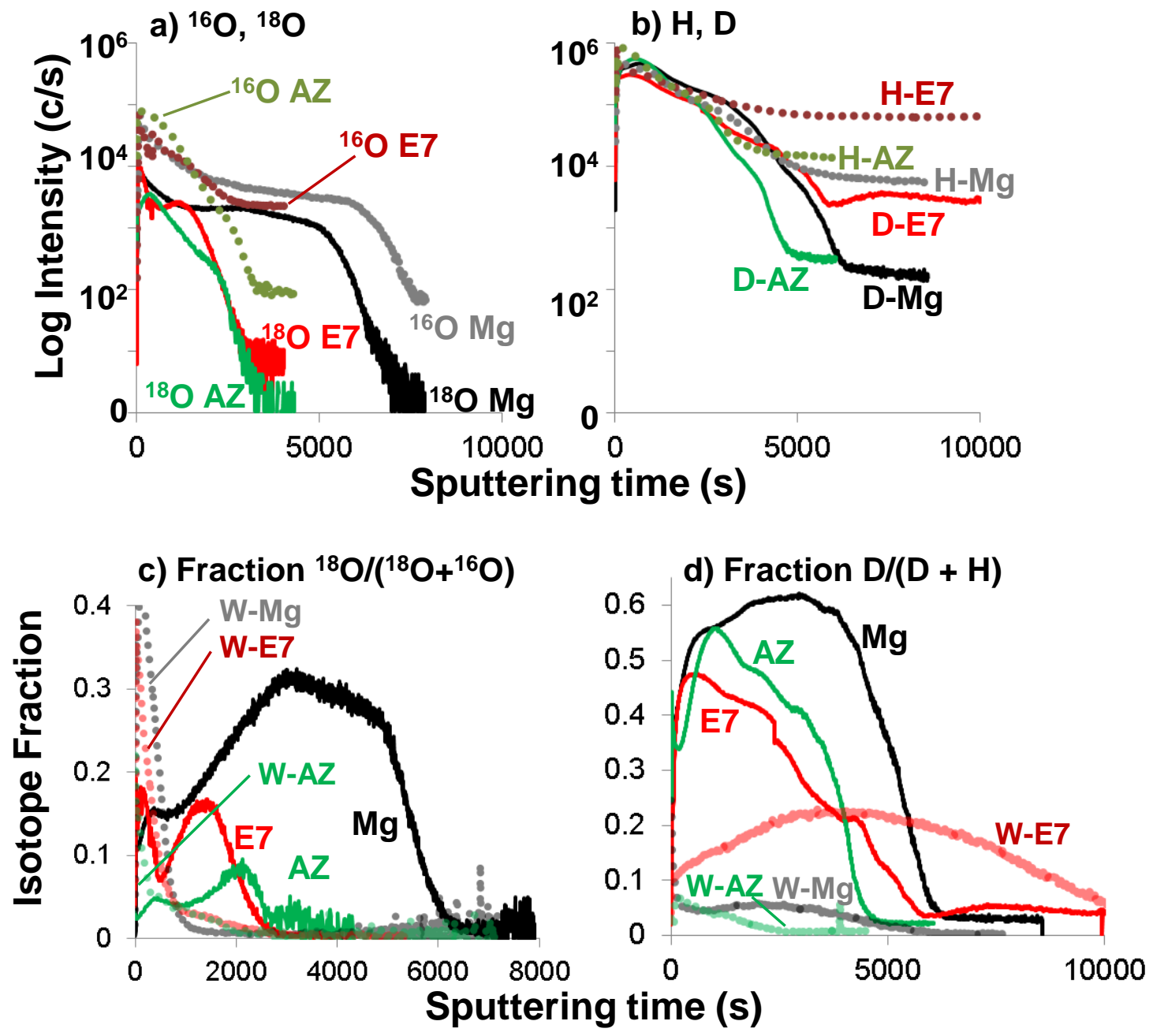

Fig. 3- SIMS data after sequential tracer $85^{\circ} \mathrm{C}$ humid air oxidation $(0.58$ bar $)$ : a) ${ }^{18} \mathrm{O}$ and ${ }^{16} \mathrm{O}$ profiles; b) D and $\mathrm{H}$ profiles; c) Fraction ${ }^{18} \mathrm{O} /\left({ }^{18} \mathrm{O}+{ }^{16} \mathrm{O}\right)$; d) Fraction $\mathrm{D} /(\mathrm{D}+\mathrm{H})$. Data marked "W" is for sequential tracer room-temperature water immersion data from [13]. $\mathrm{AZ}=\mathrm{AZ31B}, \mathrm{E} 7=$ $\mathrm{E} 717, \mathrm{Mg}=\mathrm{UHP} \mathrm{Mg}$ 